\title{
Fire Service Needs Workshop Proceedings
}

San Antonio, Texas, October 13-15, 1999

William D. Walton

Nelson Bryner

Daniel Madrzykowski

James R. Lawson

Nora H. Jason, Editors
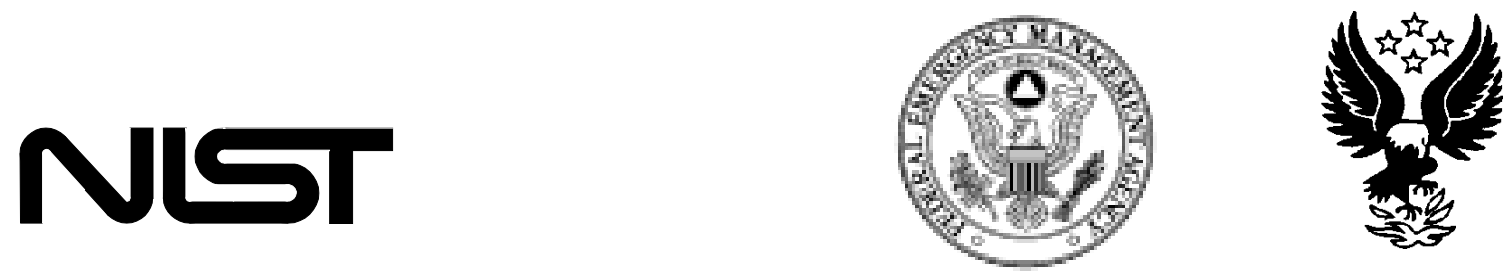

United States Department of Commerce Technology Administration

Federal Emergency Management Agency United States Fire Administration

National Institute of Standards and Technology 


\section{Fire Research Needs Workshop Proceedings}

\section{San Antonio, Texas, October 13-15, 1999}

William D. Walton, Nelson Bryner, Daniel Madrzykowski, James R. Lawson and Nora H. Jason, Editors

Building and Fire Research Laboratory

National Institute of Standards and Technology

Gaithersburg, MD 20899-8644

July 2000

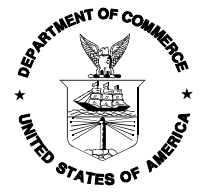

U.S. Department of Commerce

William M. Daley, Secretary

Technology Administration

Dr. Cheryl L. Shavers, Under Secretary for Technology

National Institute of Standards and Technology

Raymond G. Kammer, Director
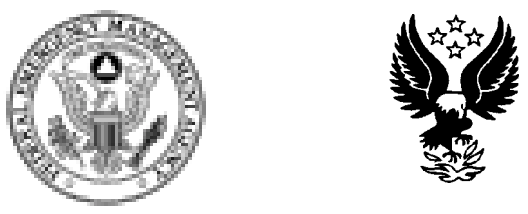

Sponsored in part by:

Federal Emergency Management Administration

James Lee Witt, Director

U.S. Fire Administration

Carrye B. Brown, Administrator 


\section{NOTICE}

This Proceedings is the official transmittal of the workshop recommendations to the co-sponsor, U.S. Fire Administration, Federal Emergency Management Agency. It reflects the combined input of the workshop participants and not necessarily the views of the U.S. Fire Administration or the National Institute of Standards and Technology. 


\section{CONTENTS}

AGENDA iv

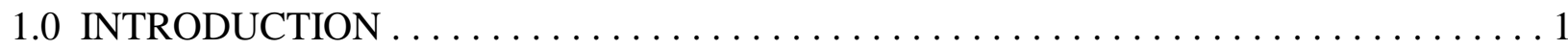

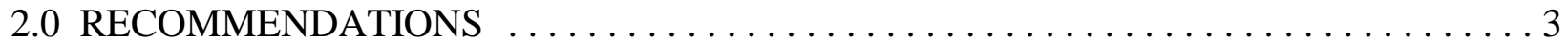

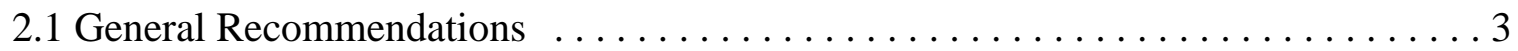

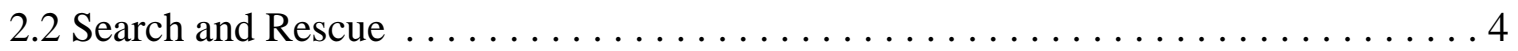

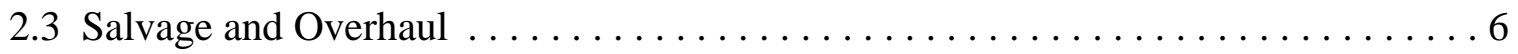

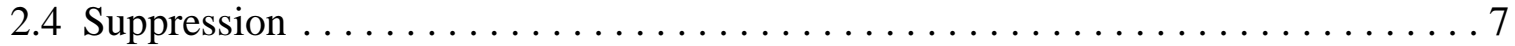

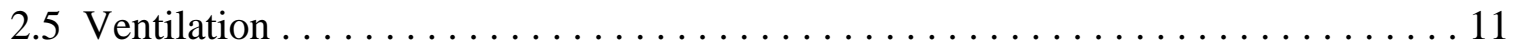

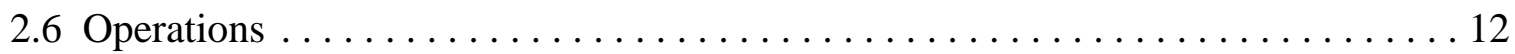

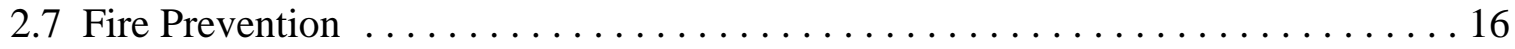

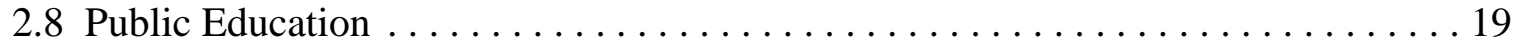

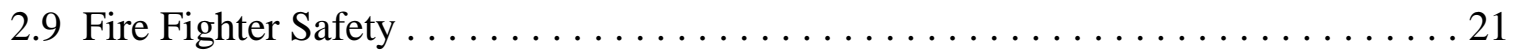

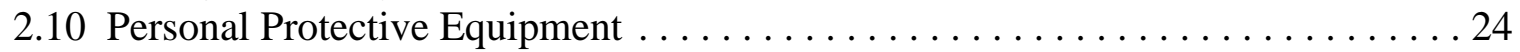

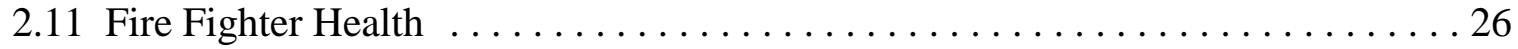

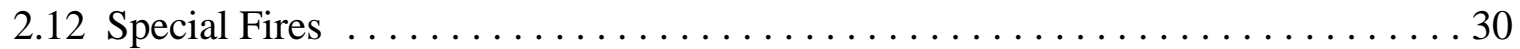

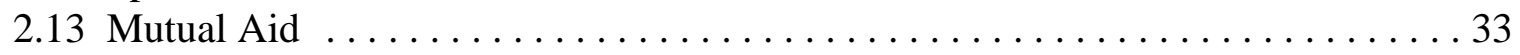

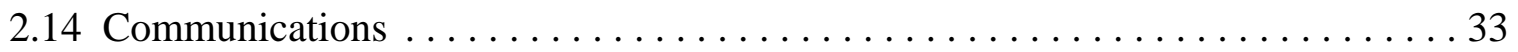

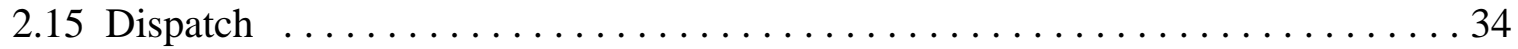

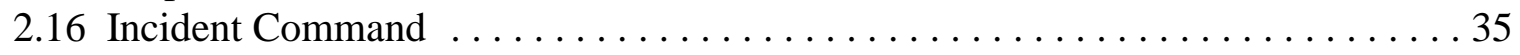

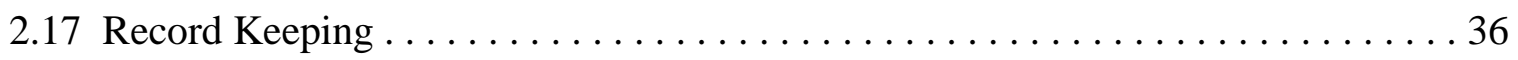

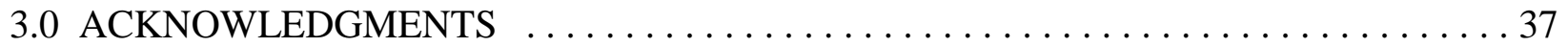

4.0 FIRE SERVICE NEEDS WORKSHOP ATTENDEES $\ldots \ldots \ldots \ldots \ldots \ldots \ldots \ldots \ldots$ 


\section{AGENDA}

\section{FIRE SERVICE NEEDS WORKSHOP \\ U.S. Fire Administration \\ San Antonio, TX \\ October 13-15, 1999}

Wednesday, October 13, 1999

\begin{tabular}{|c|c|}
\hline 08:30 AM & Registration \\
\hline 09:00 AM & Welcome - Carrye B. Brown, US Fire Administrator \\
\hline 09:15 AM & Background and Workshop Purpose - Bob McCarthy, USFA \\
\hline 09:30 AM & Introduction of Attendees \\
\hline 09:45 AM & Charge to the Workshop Panels - Doug Walton, NIST \\
\hline & $\begin{array}{l}\text { Overall considerations (tactics, equipment, new technology, codes and standards } \\
\text { testing and evaluation) }\end{array}$ \\
\hline 10:00 AM & Introductory Breakout Session - Working Panel Orientation \\
\hline 10:15 AM & Break \\
\hline 10:30 AM & $\begin{array}{l}\text { Workshop Panel Session - Firefighting Operations (search and rescue, water } \\
\text { supply, suppression, ventilation, exposure protection, salvage and overhaul), Fir } \\
\text { Session }\end{array}$ \\
\hline 12:00 noon & No Host Lunch \\
\hline 01:15 PM & Workshop Panel Session - Firefighting Operations, Second Session \\
\hline 02:45 PM & Break \\
\hline 03:00 PM & Workshop Panel Session - Firefighting Operations, Third Session \\
\hline 03:30 PM & Group Review and Discussion \\
\hline 04:30 PM & Administrative Announcements and Adjournment \\
\hline \multicolumn{2}{|c|}{ Thursday, October 14, 1999} \\
\hline 08:30 AM & Group Review \\
\hline 09:00 AM & $\begin{array}{l}\text { Workshop Panel Session - Special Fires (high rise, industrial, urban/wildland, } \\
\text { disasters, marine, crash fire rescue) }\end{array}$ \\
\hline 10:30 AM & Break \\
\hline 10:45 AM & $\begin{array}{l}\text { Workshop Panel Session - Fire fighter Health and Safety (protective clothing, } \\
\text { SCBA, PASS, building collapse, tracking, rehabilitation, fitness), First Session }\end{array}$ \\
\hline 12:15 PM & No Host Lunch \\
\hline 01:15 PM & Workshop Panel Session - Fire fighter Health and Safety, Second Session \\
\hline 02:45 PM & Break \\
\hline 03:00 PM & $\begin{array}{l}\text { Workshop Panel Session - Fire Mitigation (prevention, public education, plan } \\
\text { review, preplanning, inspections) }\end{array}$ \\
\hline 04:00 & Group Review and Discussion \\
\hline 05:00 PM & Administration Announcements and Adjournment \\
\hline
\end{tabular}


Friday, October 15, 1999

08:30 AM Group Review

09:00 AM Workshop Panel Session - Communications and Information Technology (dispatch, incident command, record keeping, mutual aid)

10:30 AM Break

10:45 AM Final Review

11:45 AM Closing Remarks

12:00 noon Adjournment 


\section{FIRE SERVICE NEEDS WORKSHOP}

San Antonio, Texas

October 13-15, 1999

\subsection{INTRODUCTION}

The mission of the United States Fire Administration (USFA) is to reduce life and economic losses due to fire and related emergencies, through leadership, advocacy, coordination with Federal agencies, and in partnership with fire protection and emergency services communities. Through Fire Administration leadership, a National Fire Research Agenda is developed with input from federal, state and local partners. Using this agenda, with a commitment to excellence, the USFA provides public education, training, technology, and data initiatives as follows:

Public Education: Develops and delivers fire prevention and safety education programs in partnership with other Federal agencies the fire and emergency response community, the media, and safety interest groups.

Training: Promotes the professional development of the fire and the emergency response community and its allied professionals. To supplement and support state and local fire service training programs, the National Fire Academy develops and delivers educational and training courses having a national focus.

Technology: Works with public and private groups to promote and improve fire prevention and life safety through research, testing, and evaluation. Generates and distributes research and special studies on fire detection, suppression and notification systems, and on fire and emergency responder health and safety.

Data: Assists State and local entities in collecting, analyzing and disseminating data on the occurrence, the control and the consequences of all types of fires. The National Fire Data Center, which administers the National Fire Incident Reporting System (NFIRS), describes the Nation's fire problem; proposes possible solutions and national priorities; monitors resulting programs; and provides information to the public and fire organizations.

The Building and Fire Research Laboratory at the National Institute of Standards and Technology conducts research related to the measurement and prediction of fire related phenomena and has a memorandum of understanding with the Fire Administration. The agreement calls for cooperation between the two agencies in the areas of planning, information exchange and technology transfer to improve fire safety.

As part of an ongoing effort to update and sharpen the National Fire Research Agenda, the Fire Administration in cooperation with the Building and Fire Research Laboratory, at the National Institute of Standards and Technology held two workshops to obtain input from the fire community. 
The first focused on the needs of the fire service and was held October 13-15, 1999, in San Antonio, Texas. At that workshop, 32 members of the fire service representing national fire service organizations and a wide range of fire departments in both size and location were asked to identify the needs of the fire service. Areas of emphasis included fire fighting operations, fire fighter health and safety, large fire incidents, fire mitigation, communications and information technology. A list of the attendees is provided at the end of this report.

The second workshop was held October $20^{\text {th }}$, 1999, in Emmitsburg, Maryland and focused on the needs of the fire protection community beyond the fire service. Representatives of professional organizations, trade associations, and building code organizations were invited to present there research needs. The findings from that workshop are presented in a separate report.

The attendees at the Fire Service Needs Workshop were divided into two panels. The panel members were preselected to provide a uniform distribution of fire department sizes on each panel. A panel chair was preselected to run the panel sessions. Each of the panels was given the same charge, which was to identify needs of the fire service. The panels were asked not to specifically address needs in the areas of financial issues, labor relations, emergency medical service, hazardous materials response, special rescue services or fire investigation. Some of these issues have been addressed in other workshops and some would best be addressed by a panel of experts in that field.

The operation of the panels was left to the panel chairs and each chair appointed an assistant. Two recorders from the Building and Fire Research Laboratory at the National Institute of Standards and Technology were assigned to each panel. The recorders were familiar with fire service issues and jargon and took the notes which served as the basis for this report. The recorders did not participate in the discussions. At the final session of the workshop the panels were combined since some participants had to leave early. A third panel chair was appointed for this session since the each of panels had developed a team spirit and it would have been difficult to merge the two panels using either of the panel chairs.

In order to ensure the panels covered the complete range of topics, the panel chairs were given a list of topic areas to be sure they addressed. The panel chairs could include other topics and reallocate the time as they saw necessary. For needs identified, the panelist were asked to rate its relative priority as high, medium or low.

The findings of the two panels were similar and were merged to form this report. Nearly identical needs identified by both panels have been combined. There is, however, some redundancy as similar needs were identified but with a different emphasis. The needs have been organized into categories to simplify reading; however, some needs span more than one category. The needs within each category have been ordered from high to low priority although the order within a priority is arbitrary. The editors of this report have made every effort to accurately record the needs as presented by the panels. No effort has been made to verify or provide references for the statements made by panel members and used in this report. 


\subsection{RECOMMENDATIONS}

2.1 General Recommendations

Need: Organize fire service leadership to be more effective in lobbying, marketing and educational efforts.

Background: The fire service needs to speak with a united voice to maximize its effectiveness. Areas which should be addressed include staffing, funding, public policy and code issues.

Priority: High

Comments: The fire service needs to select appropriate target audience (public and politicians) and not just talk to others in the fire service. The fire service needs to use data generated from completed and proposed studies to support its position.

Need: Make emerging technologies, new programs and support services available to as broad a section of the fire service as possible.

Background: There is a wide disparity in the accessability of resources between small rural, suburban combination, and municipal departments.

Priority: High

Comments: Unfunded mandates create hardships on small departments. It can be difficult to comply with National Fire Protection Association (NFPA) and Occupational Health and Safety Administration (OSHA) standards and regulations for the fire service. There is a need to explore issues on a regional basis.

Need: Change in the fire service culture.

Background: Fire safe behaviors need to be a cultural priority. Fire fighters are intensively schooled and culturally reinforced in suppression efforts. Prevention needs to be given the same priority. Modify the current fire service culture that rewards and glamorizes unsafe behaviors and migrate to a culture that rewards safe behavior.

Priority: High

Comments: Fire Service needs to speak with united voice to maximize its effectiveness. 
Need: Every issue identified in this workshop has an associated training need.

Background: Research organizations need to partner with training entities throughout the development process. This would enable better understanding of findings, conclusions, delivery of training and implementation of technology/programs.

Priority: High

Comments: Training is the principal means for conveying information and transferring technology within the fire service.

Need: Improve transfer of technology to fire departments and individual fire fighters.

Background: There are many new technologies being developed, but they are not always available to fire departments/fire fighters. There would be less effort wasted in developing duplicate technologies if current technology could be disseminated in timely and efficient manner. The fire service needs to avail itself of the government technology transfer offices.

Priority: High

Comments: New technology needs to be fire fighter friendly, intuitive, durable and easy to use. New technology needs to be continuously updated. There are specialized technologies used in urban search and rescue which may be useful in fighting structural fires.

\subsection{Search and Rescue}

Need: Develop standard search and rescue procedures which would provide principles and standard patterns for search and rescue operations.

Background: There are a wide range of search patterns and approaches used by different departments. For example, some departments search left and others search right. The problem is most acute if departments from different jurisdictions are present at the fire scene. Different search patterns could result in areas of the building being left unsearched. If a search team encounters difficulties, a second team using a different search technique could have difficulty locating the first team.

Priority: High /Medium

Comments: Departments may have different criteria for primary versus secondary searches. 
Need: Develop sensors to detect hazards in building including toxic smoke, thermal radiation, hazardous chemicals, and structural failure.

Background: Fire fighters typically arrive at an incident without adequate information on hazards in/around fire scene. First responders need to be able to quickly access hazards before beginning search and rescue and fire suppression activities.

Priority: Medium

Comments: Building preplans are not always up to date and although they may identify the building contents, they cannot indicate the conditions within the building at the time of arrival.

Need: Fire safety standards for burglar bars on windows and doors.

Background: Burglar bars are often installed on windows and doors that may serve as a means of escape during a fire. The bars are frequently fixed and cannot be opened by the building occupants in the event of a fire. In most jurisdictions there is no requirement that burglar bars have a quick release mechanism for use by building occupants in the event of a fire.

Priority: Medium

Comments: Burglar bars are most often a problem in residential and small buildings not subject to fire inspections.

Need: Develop new technology for forced entry.

Background: Means are needed to more quickly enter security doors with burglar bars so that rescue and fire suppression activities may begin.

Priority: Low/Medium

Comments: Security doors and burglar bars impede rescue and fire suppression activities. Automobile hood systems restrict access to engine compartments. 


\subsection{Salvage and Overhaul}

Need: Better understand the postfire environment.

Background: As the fire environment has changed over the past 20 years, it is reasonable to assume the postfire environment also has changed.

Priority: Medium/High

Comments: Evaluate the postfire environment in terms of atmosphere, structural stability, work methods (wait to overhaul), and proper personal protective equipment for overhaul.

Need: Develop technology to scan personnel and equipment for contamination and determine the type of decontamination required.

Background: Equipment may be exposed to hazardous materials on fire scene. It is not always obvious which equipment is contaminated and how best to decontaminate it.

Priority: Medium

Comments: Most fire fighting equipment is simply washed at the scene or at the fire station.

Need: Identify in real time hazardous levels of gaseous compounds in the postfire environment.

Background: Fire fighters know there are potentially dangerous atmospheres, but cannot qualify or quantify them at time of overhaul.

Priority: Low

Comments: Fire fighters generally remove self-contained breathing apparatus after the fire is out, potentially exposing themselves to hazardous levels of carbon monoxide and other gases. 


\subsection{Suppression}

Need: Investigate and improve water additives to improve fire fighting properties, including increasing heat capacity, and longer durability of exposure protective coating systems.

Background: Research has been conducted on agents to improve water flow in hoses; however, other agents need to be thoroughly evaluated. While some foam agents provide immediate protection to a structure, the foam dries out and flakes off with time. Additional additives may improve durability of the foam.

\section{Priority: High}

Comments: Additives are needed for both salt and fresh water applications.

Need: Develop methods to evaluate the effectiveness of alternative fire fighting agents.

Background: The only information available to the fire service on many types of agents is that which is supplied by the manufacturer.

Priority: High

Comments: There are a number of alternatives to "plain water" for fire suppression and fire control. Examples are foams, emulsifiers, gels, water additives, multiple agents, and high pressure water mist.

Need: Develop a "smart" nozzle for fire suppression, and develop ways to maximize efficiency of fire suppression delivery systems.

Background: Nozzles that supply the most efficient flow rates and patterns would assist in fire suppression tasks. Nozzles that provide feedback to the fire fighter should be investigated.

Priority: Medium

Comments: The issues that need to be studied and quantified include pressure, flow rate, spray pattern, and drop size. 
Need: Analyze and develop an accurate method of determining required flow rates for structural fire suppression.

Background: Fire growth rates appear to have changed over the last twenty years and predictive formulas need to be updated to accurately calculate realistic flow rates.

Priority: Medium

Comments: What flow rates are actually required to extinguish a given fire with different diameter hose lines.

Need: Develop a system to quickly identify the proper type of foam and application method.

Background: Currently the application of foam is not always based on a complete understanding of the capabilities of the foam for use in a given situation. There are a number of different foams available, and some fire departments may have several types of foam available. In some instances it is difficult to determine which type of foam is best for a particular fire and how to apply that foam.

Priority: Medium/Low

Comments: Training is important for the proper selection and use of foam. Upkeep and maintenance of foam systems is difficult. Foam storage and foam life limits are not fully understood. Foam concentrate and generation systems are expensive. There is a need for methods to make rapid decisions on foam use. Examine the possibility of a sensor to determine the type of foam needed or a key pad on the apparatus to select the type of foam and application method.

Need: Deliver water to the fire in an efficient and economical way.

Background: Delivering water to a fire is a key element in the fire service and yet there is still a great deal not known about the performance and reliability water delivery system components. The weight and size of water distribution system components (hose and nozzles) adds to the stress on the fire fighters.

Priority: Medium/Low

Comments: There is a need to investigate the whole system of delivering water including, drop sizes, couplings, weight of devices, nozzle design, the durability of ultralightweight hose, equipment usability, capability and reliability. Investigate the use of tracers to determine the way water is being used. 
Need: Develop standard sizes for connectors for all hoses, nozzles, standpipes, hydrants and apparatus.

Background: Non-uniformity in sizes of connectors as well as apparatus specific fittings delay or prevent quick access to water supplies.

Priority: Low

Comments: Although the issue of standardization of threads has been addressed for many years there are still a number of different "standards" and a wide variety of connector sizes. For example, many shipboard fire fighting connectors are different than those used by municipal fire departments.

Need: Explore alternatives to tanker shuttles for rural water supply.

Background: Shuttles are time consuming and provide a limited water supply.

Priority: Low

Comments: Explore the use of inexpensive dry hydrants and the use of extinguishing agents other than water.

Need: Address water supply issues related to former federal facilities that have been taken over by local governments.

Background: Distribution systems and private protection systems have not been updated or maintained generally.

Priority: Low

Comments: The state of the fire protection systems may not be considered when the facility is taken over by the local government.

Need: Study the impact of microbiological induced corrosion on private protection systems and water distribution systems.

Background: Corrosion of any kind causes reduced flows and can cause private protection systems to be less effective.

Priority: Low

Comments: Corrosion takes place slowly over a long period of time and its impact on water delivery may go unnoticed. 
Need: Evaluate methods for testing private protection systems.

Background: Current methods are cumbersome and expensive.

Priority: Low

Comments: Many fire departments do not have the resources to test private water supply and fire protection systems.

Need: Establish guidelines for use of smooth bore and fog nozzles to produce the most effective result in fire suppression.

Background: There are many opinions concerning the most effective use of smooth bore and fog nozzles in fire fighting. Little data exists that quantifies the most effective application of these fire suppression tools.

Priority: Low

Comments: Fire fighters need guidelines to assist them in selecting which type of nozzle to use for a specific fire suppression task.

Need: Improve the capability and reliability of fire apparatus water pumps.

Background: Fire service pumps have not changed a great deal in recent years. Develop information on the common failure points and maintenance needs for current pump designs.

Priority: Low

Comments: The fire service has not fully investigated the use of "new" pump technologies developed for military applications. 


\subsection{Ventilation}

Need: Understand the effective use of ventilation.

Background: Many of the tactics for ventilation have remained unchanged for years even though building construction and building contents have changed. These changes may result in more rapid fire growth and spread which may not be adequately addressed by existing tactics.

Priority: $\quad$ Medium

Comments: There is a need to evaluate existing ventilation techniques including positive pressure ventilation. Roof and high rise ventilation safety remains an issue as a cause of fire fighter injuries and fatalities. Research on ventilation techniques is needed to improve the efficiency.

Need: Explore methods other than ventilation to reduce the negative effects of smoke on visibility during fire fighter operations.

Background: Limited visibility caused by particulate matter in smoke makes suppression operations more difficult.

Priority: $\quad$ Medium

Comments: Develop a soot removal additive which, when added to air, would reduce soot in smoke.

Need: Develop reliable and economical smoke evacuation systems for residential occupancies.

Background: Smoke detectors and sprinklers are doing a good job of detecting and suppressing fires, but they do not remove the smoke. The majority of fatalities in residential occupancies are caused by smoke inhalation.

Priority: Medium

Comments: Requirements in residential occupancies are difficult to implement. 
Need: Evaluate changes in the design of positive pressure ventilation fans.

Background: Exhaust gases from gasoline engine powered positive ventilation fans frequently enter the buildings being ventilated.

Priority: Low

Comments: Exhaust gases should be routed so they are not blown into structure causing carbon monoxide poisoning. Gas engines should function and not leak fuel when positioned at various angles.

Need: Develop guidelines for most effective use of positive pressure ventilation, including when it should and should not be used.

Background: Fire fighters need to select the best method from range of choices. Information should be developed comparing positive pressure ventilation with traditional ventilation methods.

Priority: Low

Comments: Investigate the use of heating, ventilation, air conditioning and vent systems that work in conjunction with automatic suppression systems.

2.6 Operations

Need: Develop a means for fire fighters to sense and understand the thermal environment around them while fighting a fire.

Background: Fire fighters are encapsulated in their protective clothing and equipment and have lost valuable signs that help to define the thermal environment around them. This loss of perception results in fire fighters entering thermal environments that may be dangerous.

Priority: High

Comments: There are no universal guidelines indicating when a fire fighter should stop entering a high temperature area. Sensing coat technology may be useful for this purpose. Thermal conditions from the sensors should be transmitted back to the incident commander. 
Need: Study and quantify fire fighting environments that are currently being faced by the fire service.

Background: The last study on fire fighting environments was conducted about twenty years ago. Many changes have been made in building construction, materials, interior finishes, and furnishings. Fire fighting equipment and tactics have also changed over this same period.

Priority: High

Comments: Fire environments should studied for a range of occupancies. Fire spread characteristics need to be quantified and the types of materials burning should be identified. Research is needed on fire loads, heat release rates, thermal environments, combustion gases, smoke movement, gas flow conditions and pressures. This environmental information should be linked with the selection, use, and performance of fire fighters' personal protective clothing.

Need: Develop a sound criteria for assessing if an interior attack or an exterior attack is more appropriate.

Background: Fire fighter injuries and fatalities are occurring when the only life risk is that of the fire fighter.

Priority: High

Comments: There is a strong commitment on the part of the fire service to extinguish fires. This is a difficult tradition to change.

Need: Develop technologies that will make elevators a more useful tool for the fire service.

Background: Elevator use is limited by the potential danger; however, the potential for increasing the effective use of elevators is recognized. Efforts are needed to expand the capabilities of elevators for occupant evacuation and effective fire fighting.

Priority: High

Comments: Elevators need to be made more user friendly. Elevators need better fire protection, perhaps including encapsulation to protect them from the fire environment. Improvements in elevator safety may make them usable to evacuate from a fire. Improvements are needed to protect hoisting cables and systems. Standard operating procedures need to be developed for the use of elevators in fire fighting. 
Need: Develop a data repository to collect information on performance of equipment and the impact of actions.

Background: Currently there is no widespread means to determine the experience of other departments with respect to equipment problems and failures, and the effectiveness of methods, deployment and tactics.

Priority: High

Comments: The existing data bases do not provide a complete picture and are not always useful. This information would be useful in determining the reliability and durability of equipment. The fire service community cannot take full advantage of the resources and experience of the large departments.

Need: Develop a demographic profile of fire departments to assist long range planning.

Background: The governance, financial, political and social structure of fire departments are not well known. This lack of knowledge makes it difficult to develop long range plans to ensure adequate delivery of emergency services in the future.

Priority: High

Comments: A few states (e.g., Iowa) have done detailed studies which have yielded some unexpected results.

Need: Evaluate fire department response performance relative to fire behavior.

Background: Fire department location, deployment and staffing are not necessarily matched to the actual behavior of the fire. Response times are based on "rules of thumb" for fire growth and not based on research.

Priority: High

Comments: The fire service needs to know if, on average, they will arrive at the scene of a fire in time to substantially reduce the loss of life and property. 
Need: Better evaluation, standards, training, and understanding of the capabilities and limitations of thermal imaging systems.

Background: New thermal imaging devices are appearing on the market, and their use is becoming more widespread. There is a need to incorporate the use of thermal imaging units into fire ground tactics. Currently there is no effective way to evaluate different units, and there are no standards for the performance and operation of the units.

Priority: Medium

Comments: Remote transmission of images to the incident command is available on some systems, and its use needs to be further investigated. Costs of the units is still high. Combination systems including infrared, low light and video may show promise for the future.

Need: Improvements in apparatus design.

Background: Fire apparatus is getting bigger and more expensive. The use of large apparatus can limit the access to the fire scene. Standards for fire apparatus may limit the introduction of innovative design which are small and maintain the same capabilities.

Priority: Medium

Comments: The fire service needs to take advantage of military technology.

Need: Determine the extent to which it is possible for the fire service to be proficient at delivering a large number of services.

Background: The fire service is being expected to deliver more speciality services at a greater level of proficiency.

Priority: Medium

Comments: The community has the expectation that fire departments will deliver a wide variety of service in a fast and efficient manner. Although fire departments have specialized units, for example Hazardous Materials (HAZMAT) and Urban Search and Rescue (USAR), the first responding units are expected to take the appropriate action prior to the arrival of these specialized units. 


\subsection{Fire Prevention}

Need: Examine the political, social, and economic impact of requiring automatic sprinklers in all buildings.

Background: It has long been known that automatic fire sprinkler systems are an effective means for controlling or suppressing fires in buildings. Economic and political concerns have prevented the more widespread adoption of mandatary sprinkler requirements.

\section{Priority: High}

Comments: A comprehensive analysis should be conducted to compare all the costs involved including fire departments, insurance, direct and indirect loss and system cost. Many in the fire service feel that, in general, automatic fire sprinklers should be required in all new structures.

Need: Develop low cost quick response automatic extinguishing systems for residential and other occupancies.

Background: Public perception of the cost, potential for damage, and installation applicability is not accurate.

Priority: High

Comments: Improved public education is needed. Partnerships should be developed with groups such as the National Association of Home Builders (NAHB) and realtors. An issues that needs to be addressed is the fear of accidental activation. Improvements in residential suppression systems would need to be addressed in codes and standards.

Need: Develop very early fire detection systems which track changing fire conditions, reduce false alarms and increase reliability.

Background: Investigate the integration of multiple detectors (fire, gas, motion) into one unit. Detectors should be designed with self-diagnosis. Residential detectors for hearing impaired are too expensive.

Priority: High

Comments: Although residential smoke detector have contributed to reducing the loss of life in fires, there is still a substantial opportunity for improvement. 
Need: Develop support for local jurisdictions to elevate funding and activities in fire prevention through national and state policies, research and incentives.

Background: Nationally and locally fire prevention programs have not been adequately supported. Fire service leaders need to network more effectively with outside organizations to enhance support for fire prevention programs.

Priority: High

Comments: The fire service needs to investigate new partnerships with architects, builders, public officials and others. The fire service leadership and organizations need to fund these activities. Fire prevention can be self supported through fee schedules.

Need: Explore ways to develop economic partnering with private and public sectors entities to reward fire safe behavior procedures and construction.

Background: Using economic incentives may help improve compliance and raise awareness.

Priority: High

Comments: Explore relationships with the construction and insurance industries. Evaluate the impact on changes to the Insurance Services Organization (ISO) ratings of communities.

Need: Examine the demographics of fire incidents.

Background: Most fire departments recognize that there are greater instances of fires in certain areas; however, this information is frequently not used to direct fire prevention activities.

Priority: Medium/High

Comments: Issues that need to be addressed include human behavior and the incident rate in comparable communities. This could include the use of graphical information systems (GIS) to plot fire frequency, fire loss, occupancy, hazardous materials and inspection frequency demographics to indicate areas in which to concentrate fire prevention and education activities. 
Need: Develop more effective partnering with industries to incorporate improved fire safety into product design.

Background: Industry could design more fire safety into products. For example, automobile industry could include uniform and easier access to engine compartment to extinguish engine fires.

Priority: High/Medium

Comments: In many cases, fire safety and the interaction of the products with fire fighting activities are not considered in the design of new products.

Need: Develop a computer-based universal yet flexible inspection and preplan system.

Background: This development of an improved system could help deliver needed building information at the time of an incident in a uniform and understandable format.

Priority: Medium

Comments: Although there are preplan systems commercially available, there is still room for improvement. Ideally the system should be easy to use, be computer-aided design (CAD) compatible, and able to quickly produce information in a uniform format.

Need: Improve the ability to assess the risk (to the public and fire service) before and during a fire.

Background: As the number of fires have declined, the older fire officers with significant experience are retiring and the younger officers do not have the same level of experience.

Priority: Medium

Comments: There is a need to assess the risk before the fire as part of the preplan. This includes the ability to determine when offensive versus defensive tactics are in order, that is, when is it appropriate to cease firefighting operations. 
Need: Improve fire department involvement in plan review.

Background: Fire department involvement in building plan review is inconsistent across the country.

Priority: $\quad$ Medium/ Low

Comments: The impact of the fire department involvement in the plan review process is not well known. Studies are needed to show how fire department involvement in the plan review process impact the level of fire safety in a jurisdiction.

Need: Evaluate the impact of performance based codes on fire safety.

Background: The model building and fire codes in the United States are moving from prescriptive based to performance based. The impact on the level of fire safety in a community has not been demonstrated. Much of the development of performance based building codes is taking place without input from the fire service.

Priority: Medium

Comments: Countries such as New Zealand are ahead of the United States in the move to performance based codes. The impact of performance based codes on fire safety in these countries should be examined.

2.8 Public Education

Need: Quantify the effectiveness of current public education programs and their delivery systems.

Background: Fire safe behaviors need to be a cultural priority. There also is a need to explore new program development and delivery systems. Many feel the focus on and support to public education has declined.

Priority: High

Comments: There needs to be a K-12 mandated school curriculum. Partnerships need to be developed with teachers and educational associations, state departments of education, colleges, universities and others. Fire prevention issues for the elderly could be developed in partnership with the American Association of Retired Persons (AARP). Multi-cultural curriculums which are flexible enough to address local issues. Juvenile fire setters still need more emphasis. The United States Fire Administration (USFA) should re-institute annual public education conferences. 
Need: Develop strategies for better customer service and relations.

Background: Fire departments do not have the same level of public consciousness as police departments. Public awareness and fire prevention activities may only take place during Fire Prevention Week and throughout the year.

Priority: High

Comments: Develop a national marketing plan. Public education in schools is not widely used around the country. Investigate the integration of fire stations into other community buildings to increase public awareness. Returning to the community after the fire helps to reinforce fire safety and helps the community recover. There needs to be a national protocol to identify the cause of civilian fire deaths.

Need: Improve service to communities with diverse populations.

Background: Communities are a diverse collection of individuals with different languages, and culture, social, economic, and political backgrounds. The fire service has not always been quick to recognize and consider the diverse needs of the community when developing plans for delivering emergency services.

Priority: High/Medium

Comments: Many cities are rapidly changing and the fire service needs to respond to these changes in the way it delivers services.

Need: Make fire prevention and public education knowledge an integral part of every fire fighters skill set and make it culturally acceptable.

Background: Fire fighters are extensively schooled and culturally reinforced in suppression efforts. Prevention needs to be given the same priority.

Priority: High

Comments: Change fire fighter title to public safety educator. Support public education at the station level and reward fire fighter participation. Use fire fighters and teachers to deliver the program to the public. 


\subsection{Fire Fighter Safety}

Need: Improve fire ground accountability by electronically scanning personnel entering and exiting fire building.

Background: Even though there have been advances in technology in recent years, it is still difficult to track fire fighters at the fire scene. New technology is needed which automatically tracks fire fighters entering and leaving buildings. The system needs to operate without inferring with fire fighting operations or adding a burden on incident commanders.

Priority: High

Comments: Bar codes are being introduced to track cleaning and maintenance of gear.

Need: Improve fire fighter accountability through better location tracking of fire fighters.

Background: At present there is no system available to locate individual fire fighters within a building. Global positioning satellite (GPS) technology is being successfully used to track fire apparatus. Unfortunately, current GPS technology works poorly or not at all within buildings. If fire fighters become injured or incapacitated, the ability to quickly locate the fire fighters is critical for rescue.

Priority: High

Comments: The tracking system needs to be reliable, easy to use, and affordable without requiring substantial personnel or interfering with radio transmissions. It needs to track personnel in three dimensions within a building.

Need: Modify current fire service culture that rewards and glamorizes unsafe behaviors.

Background: The is a long history in the fire service of preforming heroic acts to save lives and property. However, these same acts result in unnecessary fire fighter injuries and loss of life. Even though there has been an increased emphasis on safety, acts that unnecessarily endanger fire fighters are still rewarded.

Priority: High

Comments: Modifying the current fire service culture that rewards and glamorizes unsafe behaviors is a significant challenge. The fire service needs to reward safe practices and enforcement of standard operating procedures. Safety related training needs to take place at all levels from recruits to incident commanders to the department leadership. 
Need: Develop smart personal protection equipment technology.

Background: Efforts are underway to develop systems for fire fighter accountability, tracking, remote sensing of the fire environment, remote sensing of the fire fighter's physical condition and the fire fighter's well being. Generally these systems involve individual devices with differing protocols and methods of operation. Ideally all of these systems could be combined into a single unit. This unit could possibly use a heads up display and could be combined with thermal imaging.

Priority: High

Comments: The proliferation of new technology devices with differing protocols and signals could lead to both a physical and information overload of fire fighters. A multitude of systems also presents a challenge to incident commanders who will need to provide resources to manage the information. Differing systems used by different fire departments could result in inference and confusion at large incidents.

Need: Provide awareness training for all fire fighters on weapons of mass destruction including chemical, radiological, and biological hazards.

Background: The fire service is likely to be the first on the scene at an incident involving a weapon of mass destruction. Most fire departments currently unprepared to respond to these types of incidents.

Priority: High

Comments: Although there are teams with specialized training and equipment to deal with weapons of mass destruction, it typically would be some time before they would arrive at an incident. The fire service would be expected to initially treat victims and reduce the hazard. Without proper training and equipment, it is possible the first responders could become victims of the event. 
Need: Accurate, comprehensive fire fighter injury and fatality reports.

Background: Most departments do not have adequate procedures for investigating and learning from these incidents. In many cases the investigators are too close to the case and are reluctant to expose inadequacies within the department. Many reports lack adequate details regarding the factors that contributed to injuries or fatalities.

Priority: Medium

Comments: Reports need to discuss not only the facts of the case but the impact of training and tactics which lead to the injury or fatality. For example, were the victims operating within department guidelines and were appropriate risk management principles applied? Were the decisions appropriate and were civilians lives saved as a result of injury or fatality?

Need: Develop improved driver and passenger apparatus seats.

Background: Driver and fire fighters must ride on fire apparatus wearing personal protective equipment. This makes it difficult to effectively use seat belts.

Priority: Medium

Comments: A possible resource is the United States Fire Administration (USFA) Manual on Ergonomic Apparatus Design.

Need: Develop nationally approved emergency driver training certification program.

Background: Traffic accidents remain a significant cause of fire fighter injuries and fatalities. Although some departments have excellent emergency driver training programs, there is still opportunity for improvement. Successful and effective programs could be used models.

Priority: Medium

Comments: The United States Fire Administration (USFA), National Volunteer Fire Council (NVFC) and Indiana University of Pennsylvania amongst others have programs that could serve a basis for a national program. 
Need: Develop methods for identifying and signaling the possibility for structural failure.

Background: Structural failure causes many fire fighter injuries and deaths. Tools are needed to measure and predict the possibility of structural failure.

Priority: Low/Medium

Comments: Modern buildings are constructed using technology that provides a balance between strength and cost. This has resulted in lighter structural systems such as wood truss joists using small dimensioned lumber. Structural failure may occur after relatively short burn times.

\subsection{Personal Protective Equipment}

Need: Validate thermal protective performance of protective clothing with full scale mannikin tests including different positions and various levels of dress.

Background: Current tests are conducted in the laboratory with small samples. There are some tests with mannikins, but only at one dress level and with the mannikin in the standing position. Fire fighters wear a variety of garments under protective gear and frequently operate in the crawling position.

Priority: High

Comments: Evaluate different positions including kneeling, crawling and sitting. Various levels of dress should be examined including wearing uniforms, tee shirts and shorts, and nothing under the protective clothing.

Need: Improve fire fighters personal protective equipment (PPE).

Background: Although there have been advances in personal protective in recent years, there area still areas in which the performance could be improved. Further, it is difficult to determine the expected performance of current equipment.

Priority: High

Comments: Issues that need to be addressed include: 1) the relationship between the temperatures outside and inside protective clothing, 2) the use of heat sensing devices to provide feedback on the fire environment, 3) the use of breathable versus non-breathable vapor barriers, 4) the fit of boots, 5) the interface of components from different manufacturers, 6) methods to track service life, and 7) cleaning procedures. 
Need: Better characterization of the use time for self-contained breathing apparatus (SCBA) cylinders during actual fire ground conditions.

Background: Nominal 30 minute cylinders do not usually last for 30 minutes. A more realistic rating system is needed for SCBA compressed air cylinders.

Priority: High

Comments: Most fire fighters know that the expected use time for cylinders is less than their nominal rating.

Need: Reexamine the thermal protective performance requirements and test methods in the National Fire Protection Association Standard 1971.

Background: Field testing indicates that fire fighter experience heat flux up to 4 calories and burn injuries occur from 1 calorie or less exposure. Current test protocol uses 2 calories.

Priority: Medium

Comments: More detailed studies of the fire environment encountered by fire fighters are needed. There is a tradeoff between providing increased thermal protection from the fire and increasing heat stress from heat generated by the fire fighter. The issue of the effectiveness of protective clothing after use and cleaning needs to be addressed.

Need: Improve training on the proper selection and use of personal protective equipment based upon the event.

Background: Although there have been improvements in the design of personal protective equipment, in some case the training on the limitations, use and care of the equipment has not changed.

Priorities: Medium

Comments: Personal protective equipment designed for structural fire fighting is not interchangeable with equipment designed for wildland use. 
Need: Develop fully encapsulated fire fighter protective clothing.

Background: Although modern protective clothing provides better protection than the boots, coats and helmets of a few years ago, the interface between components is a potential site for burn injuries.

Priority: Medium

Comments: One piece encapsulated protective clothing may be the trend of the future.

Need: Improve compatibility of self-contained breathing apparatus (SCBA).

Background: SCBA cylinders are not compatible between manufacturers.

Priority: Low

Comments: SCBA cylinders cannot be shared at fire incident involving different departments with SCBA's from different manufacturers.

Need: Improve respirator protection for wildland fire fighters.

Background: Fire fighters working wildland fires may require different equipment than urban fire fighters.

Priority: Low

Comments: Self-contained breathing apparatus used for structural fire fighting is generally unacceptable for use in wildland fires.

2.11 Fire Fighter Health

Need: Research to address health issues associated with radio equipment and other transmitters.

Background: There have been studies which indicate female health problems associated with $800 \mathrm{MHz}$ radios. There are rumors of problems with other technologies, but it is difficult to obtain information.

Priority: High

Comments: There have been studies such as the 1993 emergency medical study in New York City and studies with cell phones but the issue has not been resolved. 
Need: Establish and maintain fire fighter wellness and fitness programs and requirements.

Background: Fire fighters must pass entrance physicals and performance test but many departments do not have programs that continue throughout a career. Poor fitness and stress can contribute to injuries and fatalities.

Priority: High

Comments: The International Association of Fire Fighters (IAFF) and International Association of Fire Chiefs (IAFC) fitness program and the Department of Defense have developed model programs. Issues that need to be addressed include: 1) the effect of heat and cold, 2) rehabilitation recovery cycles, 3) sleep deprivation, 4) alternating work schedules, 5) length of duty times and 6) drug screening.

Need: Study occupational hazards associated with fire fighting.

Background: Occupational health hazards have been studied other occupations but not for fire fighters. There may be a need to change practices, equipment and training. There is a need for a national injury reporting system to track the nature and cause of fire fighter injuries.

Priority: High

Comments: Possible medial issues associated with fire fighting include: cancer, respiratory illness, reproductive problems, hepatitis, stress, high blood pressure, stroke, heart attack, mental health, impaired hearing, infectious diseases, burns, wounds, strains, breaks, and effects of residual products of combustion on the body.

Need: Improved techniques for conflict resolution.

Background: Conflict resolution historically has been handled without the benefit of formal training. This results in an inconsistent approach and also can lead to a escalation of problems.

Priority: High

Comments: Issues which need to be addressed include peer resolution, workplace violence and diversity training. The Occupational Health and Safety Administration (OSHA) is believed to be developing a standard. 
Need: Develop methods for improving leadership and supervision in the fire service.

Background: The fire service is migrating from an organization that just extinguishes fire to an organization that is expected to provide a wide range of emergency services with increasing professionalism. Further the fire service workforce is becoming more diverse. These transitions demand capable leaders with a wide range of skills.

Priority: High/Medium

Comments: The high level fire service leadership finds it spends a significant amount of time on personnel, budget, and other issues rather than directing fire suppression activities. These challenges require new and diverse leadership skills.

Need: Develop guidelines for rehabilitation procedures and study the effectiveness.

Background: A relatively new area of concern is the rehabilitation of fire fighters after incidents. This can include both physical and psychological rehabilitation.

Priority: Medium

Comments: Extensive studies of the rehabilitation needs for fire fighters have not been conducted.

Need: Develop techniques for dealing with external violence.

Background: Fire fighters in some areas are being exposed to increasing levels of external violence not only at the fire scene but also when they are in the community and even in the station. Fire fighters have traditionally not been given training for dealing with external violence.

Priority: Medium

Comments: Fire fighters need improved training, including how to deal with a diverse community and potentially new equipment for dealing with violence. 
Need: Improve the fire station environment.

Background: Most fire fighters spend a considerable amount of time in the fire station. The fire station is expected to serve a wide variety of purposes. Frequently these purposes are in conflict with each other since some are industrial and some are residential.

Priority: Medium

Comments: Issues include: infection control, diesel exhaust, storage of personal protective equipment, workout rooms, study rooms, rest rooms, laundry, sleeping quarters (semi-private versus bunk rooms), availability of information resources, alarm notification, separation of living quarters from other areas, noise control, kitchens, appliance shut-offs connected to alarms, automatic fire sprinklers and security.

Need: Evaluate the impact of carbon monoxide from large wildland fires on fire fighters.

Background: Wildland fire fighters do not usually use self-contained breathing apparatus. Unlike structural fire fighters, wildland fire fighters are frequently near the fire scene for long periods of time.

Priority: $\quad$ Medium

Comments: Some research indicates wildland fire fighters are exposed to high levels of carbon monoxide. Wildland fire fighters also may be exposed to elevated levels of carbon monoxide in base camps which are near the fires. These issues may apply during the overhaul after building fires.

Need: Job validated hearing test for fire fighters.

Background: Standard hearing tests have not been validated for the fire service. There is no testing and certification process for hearing aids under firefighting conditions. Hearing aids for fire fighters are subject to background noise, heat, and moisture.

Priority: Medium/Low

Comments: Hearing is critical to communications on the fire ground. Compromised communications under fire fighting conditions creates a potential threat to the safety of the fire fighter, the public and others working at the incident. 


\subsection{Special Fires}

Need: Enhance fire resistant cab design for wildland fire fighting vehicles.

Background: There have been numerous events in which fire fighters near apparatus were overrun by wildland fires. One strategy to provide a safe haven for the fire fighters is to provide apparatus with a fire resistant cab. Presently the fire exposure the cab would have withstand during a fire is not documented.

Priority: High

Comments: Wildland fires within cities are becoming an increasing problem as cities expand into the wildland environment. Fire resistant cabs could use water from the apparatus to enhance protection. Breathing air supplies may be required within the cab.

Need: Develop methods to share resources during man-made and natural disasters.

Background: Large man-made or natural disasters create conditions which exceed the capabilities of even the largest fire departments. Presently, there are only limited area systems to provide for the sharing of resources beyond normal mutual-aid agreements. Federal partners for assistance in large disasters need to be identified.

\section{Priority: High}

Comments: The two areas in which there is nationwide deployment of emergency services resources are wildland fire fighting and urban search and rescue (USAR). The units could serve as models for developing other emergency service deployments.

Need: Develop national high rise fire fighting training curriculum.

Background: Although high rise buildings have existed for a long time, fires in these buildings still present a significant challenge to fire fighters. Although some cities have excellent training programs for high rise fire fighting, many don't.

Priority: High

Comments: Issues associated with fires in high rise buildings include: 1) fire alarms and false alarms, 2) accountability for residents and fire fighters, 3) ventilation, 4) atriums, 5) exterior fire movement, 6) areas of safe refuge, 7) use of stairwells, and 8) automatic fire suppression systems. 
Need: Adapt small computer technology to the fire service.

Background: Small hand held computers are widely used in business and have many potential applications in the fire service.

Priority: High

Comments: Some of the possible areas of application include prevention, training, identifying target hazards, foam applications and fire fighter and equipment accountability.

Need: Develop information on the hazards associated with modern transportation vehicle fires.

Background: New technology is being used in automotive systems that increase dangers to fire fighters.

Priority: Medium

Comments: Modern transportation systems have items such as fuel cells, nitrogen assisted shocks, magnesium engines and structures, pneumatic bumpers, air bags that present hazards to fire fighters.

Need: Develop operational procedures for off airport aircraft fire fighting and rescue operations with structural fire apparatus.

Background: Most aircraft accidents occur off airports and away from trained crash fire fighting crews. Further most airport crash fire departments are not well trained and equipped to deal with structural fires.

Priority: Medium

Comments: Most fire departments lack the training and equipment for aircraft fire fighting.

Need: Develop a central source of information on major fire incidents.

Background: Presently, there is no central repository for the actions taken and lessons learned on major fire incidents. A central information source would allow departments to learn from the positive experiences of others.

Priority: Medium

Comments: Possible locations for the repository would be the United States Fire Administration (USFA) or the National Fire Protection Association (NFPA). 
Need: Develop disaster simulators for the public.

Background: The fire service needs more effective ways to train the public to deal with disasters such as earthquakes, tornadoes, or fires.

Priority: Medium

Comments: The Japanese have developed building simulators in which the public can experience simulated fires and earthquakes and learn the proper safety procedures. There are some programs in the United States but they do not appear to be as sophisticated as the Japanese system. The effectiveness of the use of simulators needs to be evaluated.

Need: Develop protocols for dealing with rave parties.

Background: Rave parties are a relative new phenomena and seem to be most common in the West and the Midwest. Organizers of the party rent a warehouse or outdoor area and advertise and sell tickets to the event without disclosing the exact location. On the day of the event the location is revealed using the Internet or phone message. The parties may attract thousands of attendees and generally do not have the permits, facilities and security normally required for such an event.

Priority: Medium

Comments: The large and unregulated gatherings associated with rave parties present a significant risk to both the attendees and the communities. The indoor events frequently take place in facilities in poor repair and which do not meet life safety requirements.

Need: Develop improved methods for mitigating the hazard from tire fires.

Background: A used tire storage facility fire which, if not controlled immediately, typically lasts weeks or months, and is an environmental and economic disaster. Although there have been numerous large tire fires, there is no effective way to control these fires other than isolating the burning tires and letting the fire burn out.

Priority: Medium/Low

Comments: The use of water or other suppression agents often leads to runoff which must be contained to reduce the environmental impact. 


\subsection{Mutual Aid}

Need: Shorten the dispatch request time for mutual aid.

Background: In some cases the dispatch center may not know the status of adjacent jurisdiction and cannot automatically dispatch units. Computer aided dispatch systems from different jurisdictions may not communicate with each other. Further, there is not a good way to request resources at a national level.

Priority: Low

Comments: In some cases there is no guarantee that the units responding have the expected level of training. In many cases units from different jurisdictions are unable to communicate with each other.

Need: Identify federal, state and local regulations on mutual assistance agreements.

Background: The number of laws and regulations or lack of laws and regulations may not support effective partnering among mutual assistance.

Priority: Low

Comments: There are frequently no standards or certification of units participating in mutual aid. The level of training in neighboring jurisdictions may vary greatly.

\subsection{Communications}

Need: Better communications technology.

Background: Good communications is critically important to the fire service. Although new communications technologies are continually being introduced, there are a number of areas in which problems still exist. These include communications inside buildings and tunnels, communications with fire fighters wearing selfcontained breathing apparatus, background noise, too many units using the same frequencies, and the use of mobile data terminals (MDT).

Priority: High

Comments: Good fire fighter to fire fighter and fire fighter to command communications are critical. Areas that need to be explored include new microphone technologies, repeaters within buildings and building code requirements that address communications. 
Need: Improve area- wide communications capability.

Background: In some jurisdictions there are a large number of repeaters on the same tower which result in interference. In some regions there are areas such as canyons in which communication to the central dispatch is not possible.

Priority: High

Comments: Satellite or Department of Defense technology may be able to help with these problems however, it may be too expensive to afford.

Need: Communications systems which can be configured to work in other jurisdictions.

Background: Departments responding to neighborhood communities sometimes have difficulty communicating with other dispatch centers or other incident commanders and fire fighters.

Priority: Medium

Comments: Radio frequencies allocations are governed by Federal Communications Commission (FCC) standards. There is competition with the police, municipal departments and other wireless technologies for frequencies.

\subsection{Dispatch}

Need: Improved standardized set of criteria for dispatchers.

Background: Call takers are faced with a variety of challenges. They are faced with calls in many languages and calls from people with disabilities. Further they are expected to quickly make critical decisions sometimes with incomplete information and give pre-arrival instructions. Many dispatch centers are understaffed particularly for large or multiple incidents. Critical information is not always shared with responding companies.

Priority: High/medium

Comments: Certification for dispatchers appears to be available at national level. Pre- arrival instructions are not always clear. Every department appears to want their own unique system. Liability concerns result in over-responding to minor incidents. 


\subsection{Incident Command}

Need: Reinforcement training for command officers.

Background: Recruits undergo training and senior staff undergo training, but middle level command officers often do not receive formal training for dealing with larger incidents. Middle level training is commonly received through on-the-job training or experience. Unified incident command not always implemented.

Priority: High

Comments: Training on a large scale is needed including reinforcement training for officers and incident commanders. Budget constraints sometimes eliminate officer positions and training.

Need: Utilize more sophisticated ways of delivering training to fire fighters and officers, including the use of simulators and virtual reality.

Background: Fire fighters need to understand capability and limitations of fire fighting tactics. Fewer fires result in less experience for new recruits. The military has a great deal of technology but much of it is very expensive. The opportunities for fire ground training are limited and simulation could help in training the next generation of officers. There is a need for training and simulation that can take place in the station as well as in central locations.

Priority: High

Comments: Simulators have been successfully used to train pilots and law enforcement officers. The use of simulators is very limited in the fire service and there is substantial opportunity for enhancement.

Need: Unified command understood but not always implemented.

Background: Although the unified incident command system is well developed, it is not always implemented in part due to conflicting state laws. In some cases there is confusion as to who is in charge.

Priority: Low

Comments: All agencies do not necessarily want to cooperate in the incident command system. This can be due, in part, to untrained and inexperienced command officers in agencies that are in charge. 


\subsection{Record Keeping}

Need: Improve national incident reporting system.

Background: All jurisdictions are not a part of the national incident reporting system (NFIRS). Therefore, there is no way to compile data that includes all departments. Accurate information could assist in justifying the allocation of resources to fire departments. A method of quick and efficient data entry by fire officers remains an issue.

Priority: High

Comments: There appears to be more financial support for police departments than fire departments. Complete data reporting could be used to justify increased support for fire departments. Fire departments need to market themselves better. There is an expectation that technology could assist with data entry problems. In many cases it is impractical to enter all data by hand. There is no accurate data nationwide on the makeup of fire departments. Some states do conduct a fire department census. 


\subsection{ACKNOWLEDGMENTS}

The workshop committee consisted of Bob McCarthy and Bill Troup (U.S. Fire Administration) and Doug Walton and Nora Jason (NIST). Nelson Bryner, Randy Lawson, Dan Madrzykowski and Doug Walton (NIST) carried out the difficult task of taking the notes in preparing the summary. Betty Thames (NIST) handled the travel arrangements for the panelists.

Special thanks go to the panel chairs, Kevin O'Connell and Dennis Rubin and their recorders Larry Horn and Charles Dickinson as well as Rodney Hitzselder who chaired the final session.

Finally, the panel members are to be thanked for their hard work and patience. 


\subsection{FIRE SERVICE NEEDS WORKSHOP ATTENDEES}

Fred G. Allinson, Chairman

National Volunteer Fire Council

$192304^{\text {th }}$ Avenue South

Seattle, WA 98148

tel: $206-824-6248$

fax: 206-824-2645

Mr. Samuel Aubrey, Jr.

International Association of Black

Professional Fire Fighters

4014 Rosewin Circle

Houston, TX 77047

tel: 713-923-9304

fax: 713-738-4639

e-mail: ScrSamHM22@aol.com

Asst. Chief Hank Blackwell

Santa Fe County Fire Department

15 Fire Place

Santa Fe, NM 87505

tel: 505-424-2076

fax: 505-424-2073

e-mail: hblkwell@co.santa-fe.nm.us

Captain Ferris Boardman

York Beach Fire Department

P O Box 70

York Beach, ME 03910

tel: 207-363-1014

fax: 207-363-1049

Ms. Carrye Brown, Administrator

U.S. Fire Administration

16825 South Seton Avenue

Emmitsburg, MD 21727

tel: 301-447-1018

fax: 301-447-1270

e-mail: carrye.brown@fema.gov
Mr. Nelson Bryner

National Institute of Standards and

Technology

Building 224, Room A345

Gaithersburg, MD 20899

tel: $301-975-6868$

fax: 301-975-4647

e-mail: nelson.bryner@nist.gov

Asst. Chief Ronald Carter

Oakland Fire Department

150 Frank Ogawa Plaza

Suite 3354

Oakland, CA 94612

tel: $510-238-4084$

fax: $510-238-2284$

Mr. Mike Davis

National Association of State Fire Marshals

P O Box 149104

Austin, TX 78714-9104

tel: $512-305-7906$

fax: $512-305-7910$

Chief Charles Dickinson

324 Woodstock Road

Fayetteville, PA 17222

tel: $717-352-8244$

Division Chief Raymond Durband

Sioux Falls Fire Rescue

2820 South Minnesota Avenue

Sioux Falls, SD 57105

tel: $605-367-7174$

fax: 605-367-7861

e-mail: rdu@ideasign.com 
Dr. David D. Evans

National Institute of Standards and

Technology

Building 224, Room B250

Gaithersburg, MD 20899

tel: $301-975-6897$

fax: 301-975-4052

e-mail: dave.evans@nist.gov

Mr. Mike Eversole

Congressional Fire Service Institute

900 Second St, NE, Suite 303

Washington, DC 20002

tel: $202-371-1277$

fax: 202-682-3473

e-mail: cfsi@cfsi.org

Ms. Terese Floren, Executive Director

Women in the Fire Service

4414 Regent St., $2^{\text {nd }}$ Floor

Madison, WI 53705

tel: $608-233-4768$

fax: 608-233-4879

e-mail: tfloren@wfsi.org

Mr. Stephen N. Foley

National Fire Protection Association

Public Fire Protection Division

1 Batterymarch Park

Quincy, MA 02269

tel: 617-984-7468

fax: 617-984-7468

e-mail: sfoley@nfpa.org

Chief Peter J. Ganci

Fire Department of New York

9 Metro Centre

Brooklyn, NY 11201

tel: 718-999-2068

fax: 718-999-0034
Mr. Boone Gardiner

International Society of Fire Service

Instructors

83 Mill Hill Lane

Southport, CT 06490-1224

tel: 203-259-2201

fax: 203-259-7260

e-mail: DBG@usa.net

Asst. Chief Rodney Hitzselder

San Antonio Fire Department

115 Auditorium Circle

San Antonio, TX 78205

tel: $210-912-1102$

fax: 210-207-8542

Lt. Larry Horn

Portland Fire and Rescue

Station One

55 SW Ash St.

Portland, OR 97204

tel: $503-823-3830$

fax: $503-823-3710$

Deputy Chief Theodore Jarboe

Montgomery County Fire \& Rescue Services

101 Monroe Street

Rockville, MD 20850

tel: $240-777-2400$

fax: 240-777-2415

Ms. Nora H. Jason

National Institute of Standards and

Technology

Building 224, Room A252

Gaithersburg, MD 20899

tel: $301-975-6862$

fax: 301-975-4052

e-mail: nora.jason@nist.gov 
Mr. William Killen

Naval Facilities Engineering Command 1322 Patterson Ave., SE, Suite 1000

Washington, DC 20374-5065

tel: 202-685-9259

Mr. J. Randall Lawson

National Institute of Standards and

Technology

Building 224, Room A345

Gaithersburg, MD 20899

tel: $301-975-6877$

fax: 301-975-4647

e-mail: james.lawson@nist.gov

Asst. Chief Gary Lockhart

Los Angeles County Fire Department

1320 N. Eastern Avenue

Los Angeles, CA 90063

tel: $323-881-2337$

fax: 323-881-2418

e-mail:glockhar@msn.com

Bat. Chief Emil Mack

City of Los Angeles Fire Department

2000 N. Main St., Room 1010

Los Angeles, CA 90012

tel: $213-485-6092$

fax: 213-485-9884

Mr. Daniel Madrzykowski

National Institute of Standards and

Technology

Building 224, Room A345

Gaithersburg, MD 20899

tel: $301-975-6677$

fax: 301-975-4647

e-mail: daniel.madrzykowski@nist.gov
Mr. Ernest "Buddy" Mass, VP

IAFF $11^{\text {th }}$ District

8719 Welles Edge

San Antonio, TX 78240

tel: $210-735-0545$

fax: 210-696-3040

Mr. Robert McCarthy

US Fire Administration

16825 South Seton Avenue

Emmitsburg, MD 21727

tel: $301-447-1130$

fax: 301-447-1093

e-mail: bob.mccarthy@fema.gov

Mr. Ron Morales, President

National Association of Hispanic

Firefighters

7 White Oak Drive

Clinton, CT 06413

tel: $203-576-8286$

fax: 860-669-4534

e-mail: president.nahf@snet.net

Major Kevin O'Connell

Louisville Fire/Rescue

1135 West Jefferson Street

Louisville, KY 40203

tel: $502-574-2905$

fax: $502-574-4262$

Mr. George Oster, Executive Officer

Fire Service Institute

Iowa State University

Ames, Iowa 50011-3100

tel: $515-294-6817$

fax: $800-722-7350$ 
Division Chief Kirk Owen

Plano Fire Department

P O Box 860358

Plano, TX 75086-0358

tel: $972-941-7354$

fax: 972-941-7291

Lt. Don Pelton

Harrisburg Bureau of Fire

Fire Chief's Office

123 Walnut Street

Harrisburg, PA 17101

tel: $717-567-7687$

fax: $717-255-6448$

Chief Edward P. Plauger

Arlington County Fire Department

2100 Clarendon Blvd., Suite 400

Arlington, VA 22201

tel: $703-228-3362$

fax: 703-228-7097

Captain Andy Pompe

Philadelphia Fire Department

Safety Office

5200 Pennypack Street

Philadelphia, PA 19136

tel: $215-685-8973$

fax: $215-331-4097$

Chief Joe T. Pryor

Miami-Dade Fire and Rescue 6000 South West $87^{\text {th }}$ Ave.

Miami, FL 33171

tel: $305-598-8511$

fax: 305-596-8891
Chief Dennis Rubin

Dothan Fire Department

281 East Burdeshaw St.

Dothan, AL 36303

tel: $334-793-0372$

fax: 334-712-2586

e-mail: firechief@dothan.org

Chief John Sharry

Fire Department

Lawrence Livermore National Laboratory

7000 East Avenue

P O Box 808, L-388

Livermore, CA 94550

tel: $925-423-1800$

fax: 925-422-8710

e-mail: sharry1@1lnl.gov

Bat. Chief Terry Shields

Phoenix Fire Department 150 South $12^{\text {th }}$ St.

Phoenix, AZ 85034-2301

tel: $602-262-7840$

fax: 602-534-4084

Chief Phillip Stittleburg

La Farge Fire Department

Box 9

La Farge, WI 54639

tel: $608-625-2185$

fax: 608-625-2225

Ms. Betty Thames

National Institute of Standards and

Technology

Building 224, Room A345

Gaithersburg, MD 20899

tel: $301-975-6899$

fax: 301-975-4647

e-mail: betty.thames@nist.gov 
Mr. William Troup

US Fire Administration

16825 South Seton Avenue

Emmitsburg, MD 21727

tel: $301-447-1231$

fax: 301-447-1093

e-mail: bill.troup@fema.gov

Mr. William "Doug” Walton

National Institute of Standards and

Technology

Building 224, Room A345, MS8641

Gaithersburg, MD 20899

tel: $301-975-6872$

fax: 301-975-4647

e-mail: dwalton@nist.gov 
NIST-114

(REV. 6-93)

ADMAN 4.09
U.S. DEPARTMENT OF COMMERCE NATIONAL INSTITUTE OF STANDARDS AND TECHNOLOGY

MANUSCRIPT REVIEW AND APPROVAL

INSTRUCTIONS: ATTACH ORIGINAL OF THIS FORM TO ONE (1) COPY OF MANUSCRIPT AND SEND TO THE SECRETARY, APPROPRIATE EDITORIAL REVIEW BOARD

TITLE AND SUBTITLE (CITE IN FULL)

Fire Service Needs Workshop Proceedings

San Antonio, Texas, October 13-15, 1999

CONTRACT OR GRANT NUMBER TYPE OF REPORT AND/OR PERIOD COVERED

AUTHOR(S) (LAST NAME, FIRST INITIAL, SECOND INITIAL)

Walton, W.D., Bryner, N., Madrzykowski, D., Lawson, J.R., Jason, N.H., Editors

(ERB USE ONLY)

\begin{tabular}{|l|l|}
\hline ERB CONTROL NUMBER & $\begin{array}{l}\text { DIVISION } \\
864\end{array}$ \\
\hline $\begin{array}{l}\text { PUBLICATION REPORT NUMBER } \\
\text { NISTIR 6538 }\end{array}$ & CATEGORY CODE \\
\hline $\begin{array}{l}\text { PUBLICATION DATE } \\
\text { JulY 2000 }\end{array}$ & NUMBER PRINTED PAGES \\
\hline
\end{tabular}
LABORATORY AND DIVISION NAMES (FIRST NIST AUTHOR ONLY)

Building and Fire Research Laboratory, Eire Safety Engineering Division SPONSORING ORGANIZATION NAME AND COMPLETE ADDRESS (STREET, CITY, STATE, ZIP)

U.S. Fire Administration, Federal Emergency Management Agency

Emmitsburg, MD 21727

\section{PROPOSED FOR NIST PUBLICATION}



PROPOSED FOR NON-NIST PUBLICATION (CITE FULLY)

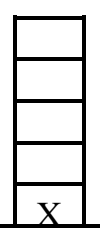

$\mathrm{X}$
MONOGRAPH (NIST MN) NATL. STD. REF. DATA SERIES (NIST NSRDS) FEDERAL INF. PROCESS. STDS. (NIST FIPS) LIST OF PUBLICATIONS (NIST LP) NIST INTERAGENCY/INTERNAL REPORT (NISTIR)

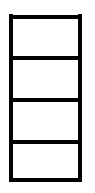
LETTER CIRCULAR BUILDING SCIENCE SERIES PRODUCT STANDARDS OTHER

PERFORMING ORGANIZATION (CHECK (X) ONE BOX) $X$ NIST/GAITHERSBURG NIST/BOULDER JILA/BOULDER



SUPPLEMENTARY NOTES

ABSTRACT (A 2000-CHARACTER OR LESS FACTUAL SUMMARY OF MOST SIGNIFICANT INFORMATION. IF DOCUMENT INCLUDES A SIGNIFICANT BIBLIOGRAPHY OR LITERATURE SURVEY, CITE IT HERE. SPELL OUT ACRONYMS ON FIRST REFERENCE.) (CONTINUE ON SEPARATE PAGE, IF NECESSARY.)

As part of an ongoing effort to update and sharpen the National Fire Research Agenda, the U.S. Fire Administration in cooperation with the Building and Fire Research Laboratory, at the National Institute of Standards and Technology held two workshops to obtain input from the fire community. The first focused on the needs of the fire service and was held October 13-15, 1999, in San Antonio, Texas. At that workshop, 32 members of the fire service representing national fire service organizations and a wide range of fire departments in both size and location were asked to identify the needs of the fire service. Areas of emphasis included fire fighting operations, fire fighter health and safety, large fire incidents, fire mitigation, communications and information technology. The attendees worked in two panels and identified more than 100 needs and their relative priorities which the editors of this report have recorded as presented by the panels. The second workshop was held October 20, 1999, in Emmitsburg, Maryland and focused on the needs of the fire protection community beyond the fire service. The proceedings of that workshop are contained in NISTIR 6539.

KEY WORDS (MAXIMUM OF 9; 28 CHARACTERS AND SPACES EACH; SEPARATE WITH SEMICOLONS; ALPHABETIC ORDER; CAPITALIZE ONLY PROPER fire departments, fire fighters, fire fighting, fire research, fire safety, fire service, technology transfer

\section{AVAILABILITY}



\section{UNLIMITED} ORDER FROM SUPERINTENDENT OF DOCUMENTS, U.S. GPO, WASHINGTON, DC 20402 ORDER FROM NTIS, SPRINGFIELD, VA 22161
NOTE TO AUTHOR(S): IF YOU DO NOT WISH THIS MANUSCRIPT ANNOUNCED BEFORE PUBLICATION, PLEASE CHECK HERE. 




